\title{
Aseptic mediastinal cyst caused by BioGlue 7 months after cardiac surgery
}

\author{
A. Szafranek, MD, S.R. Podila, FRCS, W. Al-Khyatt, MD, and E.N. Kulatilake, FRCS, Cardiff, United Kingdom
}

$\mathrm{W}$

e present a patient who had a massive mediastinal cyst 7 months after surgical intervention caused by BioGlue (CryoLife Inc, Atlanta, Ga.) residue. He was referred to us as having a "mediastinal abscess." On the basis of the size and localization of the cyst, we drained it, and during the procedure, artificial material was found within the cavity.

\section{Clinical Summary}

A 66-year-old man who underwent coronary artery bypass grafting and removal of thrombus from the apex of the left ventricle was readmitted to the hospital 7 months after the original operation complaining of a cystic swelling of sudden onset in the lower part of the sternotomy scar (Figure 1).

The swelling was $5 \mathrm{~cm}$ in diameter, cystic, and tender. There was no pulsation or redness.

The ultrasonographic report was suggestive of false aneurysmal dilatation of one of the intercostal arteries, and chest computed tomographic (CT) scanning was performed for the venous and arterial phase (Figure 2), which showed that there was a collection in the anterior mediastinum of $8 \mathrm{~cm}$ in diameter. All radiologic features were suggestive of an abscess. The patient was apyrexial, with a normal level of plasma inflammation markers.

Needle aspiration produced $150 \mathrm{~mL}$ of thick gray-colored fluid. Microbiologic analysis of the specimen revealed no bacterial growth, and fluid contained predominantly polymorphic leucocytes.

Postaspiration chest CT scanning showed that the anterior mediastinal collection was smaller and now measured about $6 \mathrm{~cm}$ in diameter. The overlying subcutaneous swelling almost disappeared. However, in 24 hours, the cyst became full and tender again and caused discomfort to the patient.

Thoracoscopic exploration was then carried out, and thick creamy fluid was drained from the subcutaneous cyst. Partial resection of the xiphoid allowed us to insert a 5-mm telescope into the retrosternal cavity. The cavity contained clear fluid and a dark, hard, irregular mass of artificial material $(2 \mathrm{~cm}$ in diameter). The mass was removed piecemeal.

A drain was left in the cavity for 1 week.

From the Department of Cardiac Surgery, University Hospital of Wales, Cardiff, United Kingdom.

Received for publication Oct 23, 2005; revisions accepted Nov 26, 2005; accepted for publication Dec 9, 2005.

Address for reprints: Adam Szafranek, 169 Beaufort Sq. Cardiff CF242TX, United Kingdom (E-mail: asza@mac.com).

J Thorac Cardiovasc Surg 2006;131:1202-3

$0022-5223 / \$ 32.00$

Copyright $\odot 2006$ by The American Association for Thoracic Surgery doi:10.1016/j.jtcvs.2005.12.054

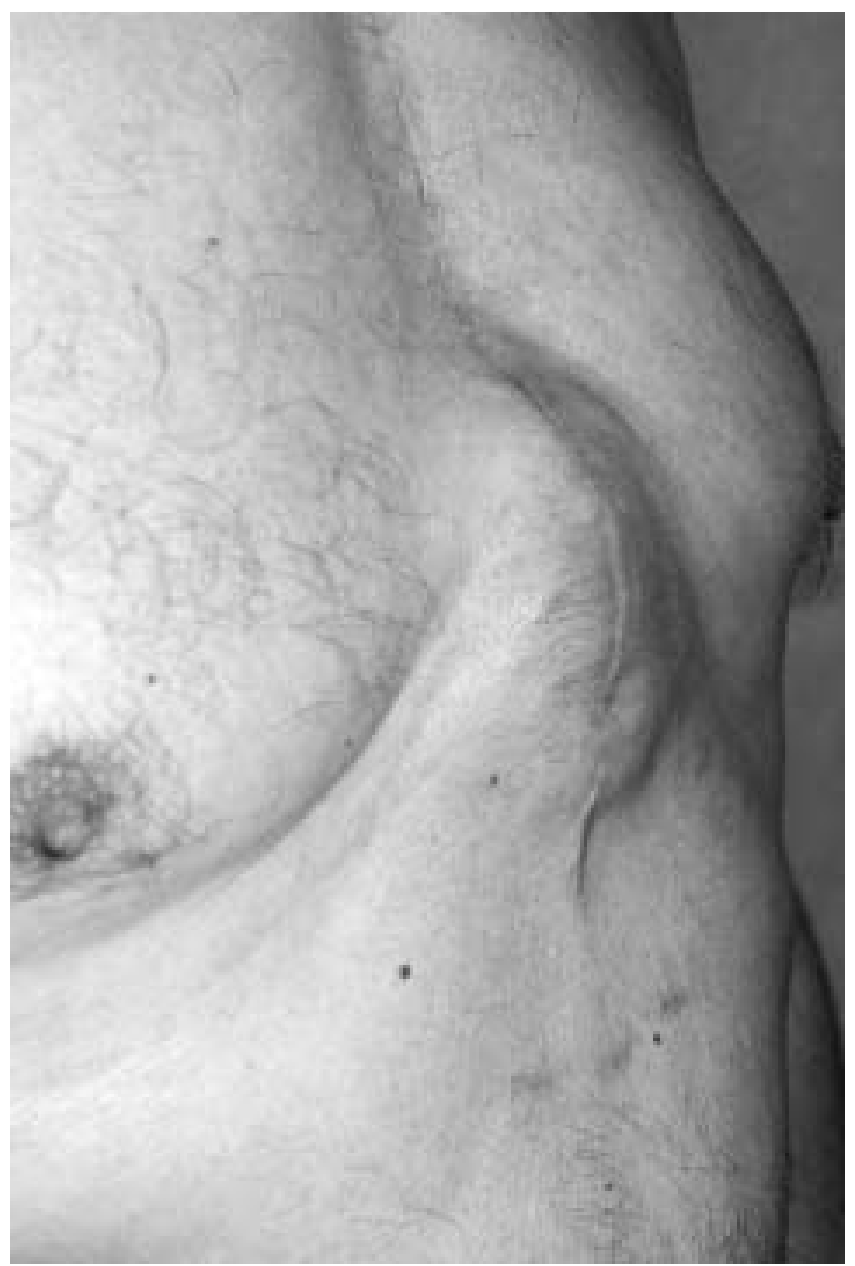

Figure 1. Cystic swelling in the lower part of the sternotomy scar.

A third chest CT scan was performed 1 month after the second operation, which showed complete absence of mediastinal collection.

\section{Discussion}

BioGlue is a surgical adhesive that combines 2 agents with distinct properties, and the compounds become active once they are mixed. The glue is approved for use in North America and Europe and recently has become very popular as a solution for difficult bleeding complications.

In our case BioGlue was used to reinforce the suture line of the left apical ventriculotomy before going off bypass. Our patient had an uneventful recovery and was discharged home on the seventh 


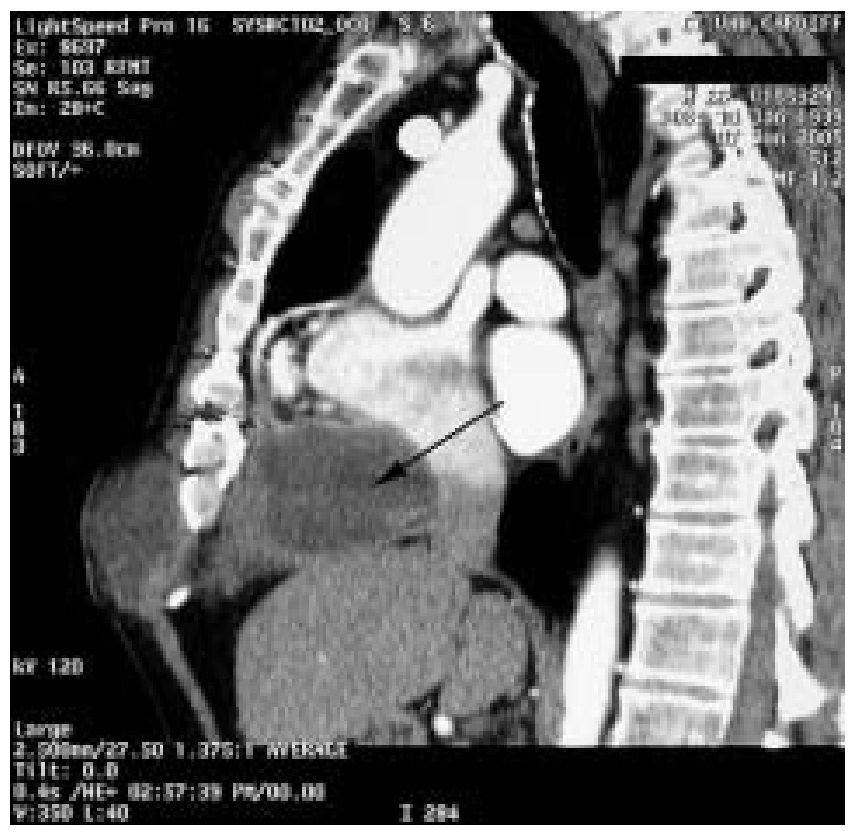

Figure 2. Chest computed tomographic scan before the second operation with mediastinal cyst.

postoperative day. When he returned 7 months after the operation with a probable abscess over the lower sternal incision, we were confident that he would require debridement because of mediastinitis. Having performed microbiologic and radiologic diagnostics. we decided to explore the cyst with the least invasive technique. A thoracoscopic technique allowed us to drain the cyst, and we found a foreign body within the cavity.

There are a variety of responses to BioGlue; a few authors describe massive foreign-body inflammatory responses in the sur- roundings of the glue, with histiocytes and granulocytes full of glue remnant. ${ }^{1}$ From recently published articles describing histologic reaction to glue, it is still not clear whether this response has any adverse effect on patients. In our case a patient had to be exposed to surgical intervention again, and fortunately, his symptoms were limited only to pain and discomfort. We believe that if this cyst had developed in different site, it could have been as dangerous as acute tamponade or mediastinitis.

The aorta is the only place where the use of BioGlue has been approved., ${ }^{2,3}$ Some authors found only weak reaction within aortic tissue. ${ }^{1,4}$ However, in tissues with cells having less collagen and elastin, the reactive response can lead to massive inflammation and collection of fluid. ${ }^{5}$ The reaction seems to be dependent on the individual but needs to be considered in every case.

There is a tendency toward an increased use of artificial glue. Some surgeons frequently use it to enhance hemostasis before going off bypass. We believe that in some cases using glue might help to avoid longer operation time, blood product transfusion, and complications related to bleeding; however, it should be limited to cases in which it is absolutely indicated.

\section{References}

1. Hewitt CW, Marra SW, Kann BR, et al. BioGlue surgical adhesive for thoracic aortic repair during coagulopathy: efficacy and histopathology. Ann Thorac Surg. 2001;71:1609-12.

2. Kazui T, Washiyama N, Bashar AHB, et al. Role of biologic glue repair of proximal aortic dissection in the development of early and midterm redissection of the aortic root. Ann Thorac Surg. 2001;72:509-14.

3. Downing SW. What are the risks of using biologic glues? Ann Thorac Surg. 2003;75:1063-4.

4. Gundry SR, Black K, Izutani H. Sutureless coronary artery bypass with biologic glued anastomoses: preliminary in vivo and in vitro results. J Thorac Cardiovasc Surg. 2000;120:473-7.

5. Fürst W, Banerjee A. Release of glutaraldehyde from an albuminglutaraldehyde tissue adhesive causes significant in vitro and in vivo toxicity. Ann Thorac Surg. 2005;79:1522-9. 